ЕВЕНКО Сергей Леонидович - доктор психологических наук, профессор; заведующий кафедрой социологии Военного университета МО РФ (123001, Россия, г. Москва, ул. Б. Садовая, 14; PVRazоv@ fa.ru)

ПОПОВ Игорь Александрович - кандидат исторических наук, доцент; доцент кафедры эвакуации и вождения военных гусеничных и колесных машин Омского автобронетанкового инженерного института МО РФ (644098, Россия, г. Омск, пос. Черемушки, ул. 14-й Городок, 119; ророv1784@ mail.ru)

\title{
ГОСУДАРСТВЕННЫЕ СТРАТЕГИИ УПРАВЛЕНИЯ РИСКАМИ СОЦИАЛЬНОЙ АДАПТАЦИИ РОССИЙСКИХ ВОЕННОСЛУЖАЩИХ, УВОЛЕННЫХ В ЗАПАС
}

\begin{abstract}
Аннотация. В статье определяются и рассматриваются различные подходы к государственному регулированию процесса социальной адаптации военнослужащих, уволенных в запас, а также членов их семей. Теоретической основой статьи выступает концепция социального планирования, расширенная в рамках рискологического подхода. В своих рассуждениях авторы опираются на результаты социологического исследования, проведенного методом экспертного опроса. В заключение дается характеристика эффективности существующих механизмов социальной поддержки указанной группы. Также авторы приводят новые перспективные направления государственного регулирования процесса адаптации уволенных в запас, а также членов их семей.
\end{abstract}

Ключевые слова: механизмы управления, система управления, социальная защита, социальная адаптация, уволенные в запас военнослужащие

$\mathrm{P}$ езультаты ежегодных социологических исследований по проблемам как правового, так и социально-экономического положения уволенных в запас военнослужащих демонстрируют их недостаточную приспособленность к условиям жизни в гражданской среде. Данные трудности невозможно решить без государственной поддержки. Так, вопросы социальной защиты и социального обеспечения бывших военнослужащих находят свое отражение в ряде стратегически важных документов, таких как Военная доктрина, а также Стратегия социального развития Вооруженных Сил Российской Федерации на период до 2020 года. Согласно данным документам, развитие и совершенствование Вооруженных сил России связывается в т.ч. и с повышением уровня жизни граждан, уволенных с военной службы.

Проведенный в рамках исследования экспертный опрос показал, что в современной России решению проблем социальной адаптации бывших военнослужащих уделяется недостаточно внимания (см. рис. 1).

Как видно из рис. 1, абсолютное большинство экспертов считают, что на текущий момент данной проблеме уделяется совсем мало внимания (76\%).

Интересен тот факт, что ни один из опрошенных не указал на достаточное внимание к проблеме бывших военнослужащих со стороны государства. Причем среди отрицательно настроенных экспертов большинство находится в возрастной категории до 48 лет; с 49 лет и старше недовольных сложившейся ситуацией несколько меньше - 56\%. Наиболее высокий процент неудовлетворенных государственной политикой в отношении проблем бывших военнослужащих можно отметить среди экспертов в звании майора (89\%), в звании подполковника таковых оказалось $67 \%$, а в звании полковника $-75 \%$.

С одной стороны, наиболее эффективными мерами повышения социальной адаптации бывших военнослужащих с точки зрения экспертов являются: инте- 


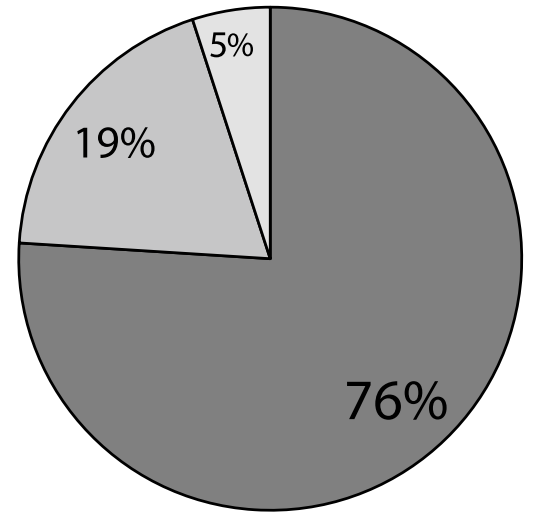

$\square$ Совсем мало уделяется внимания данной проблеме

Определенное внимание уделяется, но его не достаточно

Рисунок 1. Линейное распределение ответов экспертов на вопрос: «Как Вы полагаете, в современной России достаточно ли уделяется внимания проблеме социальной адаптации граждан, уволенных с военной службы?»

Разработка и внедрение новых форм и технологий социальной работы

Государственное регулирование рынка труда

Развитие системы переподготовки и повышения квалификации

Реформа и модернизация пенсионной системы

Реформирование Трудового кодекса РФ

Повышение престижа воинской службы и профессии военного в России

Другое

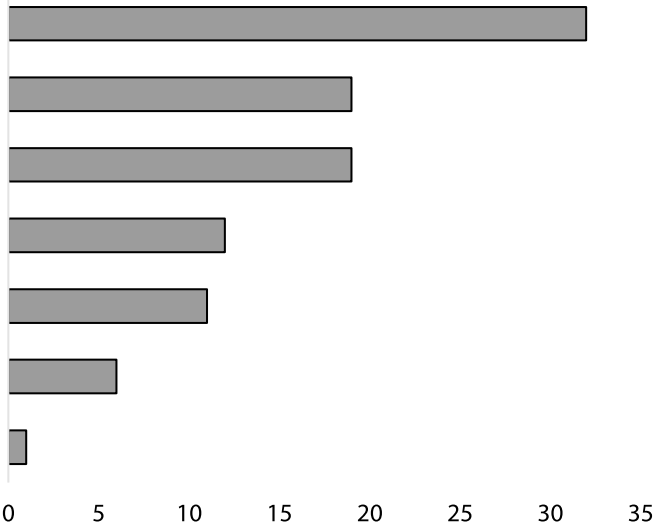

Рисунок 2. Наиболее значимые меры и направления повышения эффективности социальной адаптации бывших военнослужащих, \%

грирование новых форм и технологий социальной работы с уволенными военнослужащими (32\%); государственное регулирование рынка труда и развитие системы переподготовки и повышения квалификации кадров (по 19\% соответственно) (см. рис. 2).

При этом наименее значимым оказалось повышение престижа воинской службы и профессии военного, на которое указали лишь 6\% экспертов. С другой стороны, среди наиболее эффективно реализуемых государством мер, как указали эксперты, является именно повышение престижа воинской профессии, а разработка и внедрение новых технологий и форм социальной работы на практике оказываются не в приоритете у государства (см. рис. 3).

Задачи в области оптимизации системы социальной защиты и социального обеспечения бывших военнослужащих находятся в ведении конкретных государственных органов и структур. Вместе с этим технология управления социальной адаптацией бывших военнослужащих подразумевает, что социальная защита и социальное обеспечение данной группы граждан по большей мере 
Повышение престижа воинской службы и профессии военного в России

Государственное регулирование рынка труда

Развитие системы переподготовки и повышения квалификации

Реформирование Трудового кодекса РФ

Реформа и модернизация пенсионной системы

Разработка и внедрение новых форм и технологий социальной работы

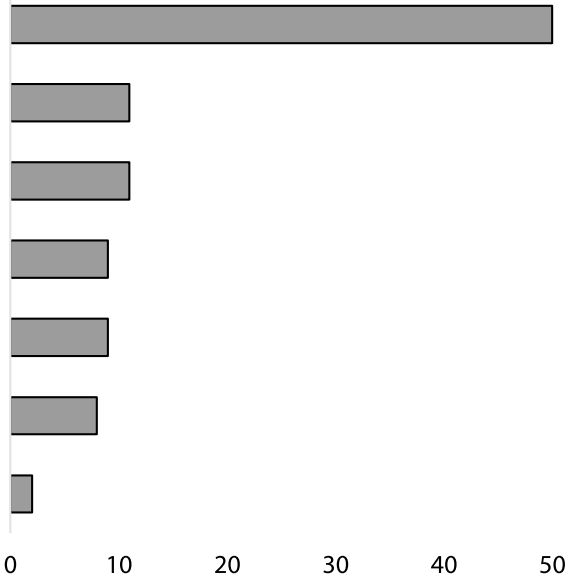

Рисунок 3. Наиболее реализуемые государством меры повышения эффективности социальной адаптации бывших военнослужащих, \%

нацелена на поощрение добросовестной службы и на восполнение ряда их общегражданских прав и свобод. Иными словами, для социальной защиты военнослужащих характерны увеличенные размеры компенсационных выплат по сравнению с прочими категориями населения.

По мнению экспертов, система материального обеспечения военнослужащих и членов их семей представляет собой аналог системы минимальных социальных гарантий гражданского населения (см. табл. 1).

Таблица 1

\section{Элементы системы социальной защиты военнослужащих и членов их семей}

\begin{tabular}{|c|c|c|c|}
\hline $\begin{array}{c}\text { Охрана жизни } \\
\text { и здоровья }\end{array}$ & $\begin{array}{l}\text { Пенсионное } \\
\text { обеспечение }\end{array}$ & $\begin{array}{l}\text { Материальное } \\
\text { обеспечение }\end{array}$ & $\begin{array}{c}\text { Обеспечение } \\
\text { жильем }\end{array}$ \\
\hline $\begin{array}{c}\text { Обязательное } \\
\text { государственное } \\
\text { обеспечение }\end{array}$ & За выслугу лет & Денежное довольствие & Служебным \\
\hline \multirow{2}{*}{$\begin{array}{l}\text { Медицинское } \\
\text { обеспечение }\end{array}$} & По инвалидности & $\begin{array}{c}\text { Профессиональные } \\
\text { выплаты }\end{array}$ & \multirow{2}{*}{ Постоянным } \\
\hline & $\begin{array}{c}\text { По случаю потери } \\
\text { кормильца }\end{array}$ & Премии & \\
\hline
\end{tabular}

Ретроспективный анализ, проведенный Т.А. Чертушкиной, позволил ей прийти к выводу, что «развитие социальной работы и пенсионного обеспечения военнослужащих, уволенных в запас, и членов их семей непосредственно взаимосвязано с развитием вооруженных сил в стране, состоянием ее экономики, уровнем национального дохода и повышением материального благосостояния людей» [Чертушкина 2014]. Помимо этого, ученому также удалось выделить ключевые тенденции в области развития социальной работы с данной категорией военнослужащих:

- неравномерность внимания со стороны как государства, так и общества к решению проблем социальной поддержки бывших военнослужащих;

- обратно пропорциональная зависимость объема материальной помощи бывшим военнослужащим от ведения военных действий государством; 
- взаимосвязь социальной поддержки бывших военнослужащих и членов их семей со значимостью армии для государства.

Одним из направлений социальной работы считается военно-социальная работа, которую В.М. Корякин рассматривает в двух формах - расширенной и узкой. Первая предполагает «создание благоприятных условий жизнедеятельности каждого военнослужащего и его семьи», вторая - информационную, консультационную, педагогическую, психологическую поддержку, а также помощь в натуральном выражении, оказываемую уволенным в запас военнослужащим и членам их семей [Корякин 2004: 18].

Очевидно, что военно-социальная работа должна выступать важнейшей частью социальной политики государства (в частности, военно-социальной политики). Законодательство Российской Федерации определяет, что именно на плечи государства возложена ответственность за проведение социальной политики и социальной защиты военнослужащих. Однако, как отмечают исследователи, не все конституционные права и социальные гарантии военнослужащих, в частности бывших военнослужащих, реализуются в полной мере. Так, Корякин указывает, что стране необходима новая концепция военно-социальной политики, направленная на повышение эффективности и устойчивости военной организации государства. Таким образом, объектом военно-социальной политики являются граждане государства, связанные (действующие военнослужащие) или ранее связанные (бывшие военнослужащие) с деятельностью военной организации. Субъектами военно-социальной политики, в свою очередь, выступают государство, играющее ключевую роль, органы военного управления, местного самоуправления, общественные организации (религиозные, благотворительные и т.д.).

На основании этого можно сделать вывод, что военно-социальная политика государства занимает важное место в системе управления социальной адаптацией уволенных в запас военнослужащих. В данном случае для минимизации рисков социальной адаптации в отношении указанной категории граждан значимую роль будут играть методы социального планирования, проектирования и программирования.

Управление социальной адаптацией уволенных в запас военнослужащих и членов их семей Ю.Я. Таран определяет как деятельность, целенаправленно проводимую на всех уровнях социального управления и ориентированную на создание условий для успешного интегрирования бывших военнослужащих в гражданскую среду. В дополнение к этому такая деятельность предусматривает изменение и самой среды в соответствии с потребностями ее членов [Таран 2007]. Однако с учетом рискологического подхода, примененного в данной работе, управление социальной адаптацией военнослужащих, уволенных в запас, можно определить «как направление в сфере социального управления, связанное с деятельностью, ориентированной на создание благоприятных условий интеграции уволенных с военной службы военно служащих в гражданскую среду путем снижения рискогенности адаптивной ситуации и самой среды с учетом ценностей и потребностей ее представителей» [Разов 2015].

Под социальным планированием понимается аспект социального управления в форме регулятора социальных процессов, взаимосвязанных с жизнедеятельностью населения и взаимообусловленных. Важнейшей функцией социального планирования является оптимизация социально-экономических процессов и повышение эффективности функционирования социальных групп.

Ж.Т. Тощенко систематизировал соответствующие подходы на основании их сущности с точки зрения социального проектирования. Среди них 1) объек- 
тивно ориентированный, 2) проблемно ориентированный, 3) субъективно ориентированный подходы [Тощенко 2011].

Первый подход заостряет внимание на процессе разработки проектов локальной социальной реальности с четким обоснованием нормативных требований.

Второй подход во главу угла ставит выработку вариантов решений как существующих, так и перспективных социально значимых реальных проблем.

Третий подход концентрирует внимание на учете субъективного видения действительности. При этом основная роль отводится учету установок, стремлений и ценностных ориентиров субъектов, вовлеченных в проектную деятельность в качестве ее созидателей.

Отметим, что в российской реальности субъектная роль в социальном планировании в большей степени сосредоточена в руках федеральных органов власти. То есть, на федеральном уровне власти происходит социальное планирование. В случае управления адаптацией военных, уволенных в запас, социальное планирование производит Министерство обороны России.

Исходя из данного положения, сделаем вывод, что в РФ применяется первый подход к социальному проектированию. На наш взгляд, именно эта модель социальной политики является наиболее приемлемой.

Кроме того, следует уточнить, что существуют различные модели социальной политики. Раскроем их на примере западных стран: 1) континентальная модель (Германия), 2) либеральная модель (Великобритания), 3) социал-демократическая модель (Швеция). Основное отличие между ними заключается в различном подходе к решению вопроса о распределении ответственности между государством и населением.

Для России же либеральный подход видится неприменимым ввиду особой роли государства в решении социальных проблем - в первую очередь из-за того, что минимизация вмешательства государства в социальную сферу обязывает к осуществлению жесткого разграничения ответственности между властными уровнями за решение возникающих социальных проблем, а также возложению основной ответственности за благополучие населения на плечи самих граждан.

В то же время остается открытым вопрос: можно ли свести систему социальной защиты со стороны государства к минимальной поддержке небольшой по численности группы населения, которая должна самостоятельно доказать необходимость получения ею адресной помощи?

Как было отмечено ранее, граждане, уволенные с военной службы, и члены их семей в значительной степени нуждаются в государственной социальной поддержке, которая воплощается через мероприятия, способствующие их социальной адаптации. Парадоксально то, что, оставаясь трудоспособной и экономически активной частью населения, эти люди оказываются невостребованными. Иными словами, данная социальная группа способна поддержать экономическое развитие страны, следовательно, от их благополучия в определенной степени будет зависеть успешность реализации проектов социальноэкономического развития.

В вопросе социальной адаптации Министерство обороны РФ как субъект социального планирования опирается на программные документы. Прежде всего, это Стратегия социального развития Вооруженных Сил Российской Федерации на период до 2020 года ${ }^{1}$. Основное место в Стратегии социального развития Вооруженных сил РФ отводится человеку и удовлетворению его потребностей в наиболее важных областях жизнедеятельности, таких как

\footnotetext{
${ }^{1}$ Стратегия социального развития Вооруженных Сил Российской Федерации на период до 2020 года. Утв. решением коллегии Министерства обороны РФ от 28.03.2008. Доступ: https://sc.mil.ru/ social/strategy.htm (проверено 25.05.2020).
} 
культура, спорт, образование, медицина, безопасность, социально-бытовые условия (в т.ч. жилищные условия), а также проблемы, связанные с денежным довольствием, заработной платой и пенсией, социальной защитой.

В отдельный пункт в Стратегии вынесены мероприятия, ориентированные на социальную поддержку указанной социальной группы. В частности, обратимся к следующим мерам по оказанию помощи бывшему военнослужащему в получении профессиональных навыков по гражданской специальности:

- развитие регионального комплекса военно-учебных центров;

- формирование сети подготовительных отделений при образовательных учреждениях высшего профессионального образования;

- переподготовка военнослужащих по гражданским специальностям в период прохождения военной службы по призыву.

Несмотря на это, сегодня не все из указанных социальных аспектов перехода к рыночным отношениям курируются государством [Разов 2015], вследствие чего во многом болезненные экономические, социальные и другие процессы, происходящие в обществе, стали причиной возникновения проблем социальной адаптации. К тому же административный принцип, действующий в социальном планировании адаптации граждан, уволенных с военной службы, и их семей, нельзя назвать эффективным, а следовательно и предпочтительным.

Подводя итог, отметим, что в вопросе управления социальной адаптацией уволенных в запас военнослужащих важнейшее место занимает военно-социальная политика. С точки зрения прогнозирования и последующего регулирования рисков адаптации указанной категории российских граждан особое место отводится технологиям социального планирования, проектирования и программирования. Планирование системы управления социальной адаптацией должно основываться на научно обоснованном определении целей, показателей, сроков, пропорций и основных средств их воплощения в жизнь.

Однако, как показал экспертный опрос, сегодняшний потенциал социальных технологий не задействован в полной мере. Таким образом, не только снижается эффективность всей российской военно-социальной политики, но в целом повышается степень неопределенности и рискогенности процесса адаптации военнослужащих, уволенных в запас, к современным российским условиям.

\section{Список литературы}

Корякин В.М. 2004. Военно-социальная работа в Вооруженных силах Российской Федерации: вопросы теории и практики: учебное пособие. М. 136 с.

Разов П.В. 2015. Риски социальной адаптации военнослужащих, уволенных в запас, к условиям гражданской жизни в России и стратегии их преодоления: дис. ... Д.соц.н. Ростов н/Д: Изд-во ЮФУ. 354 с.

Таран Ю.Я. 2007. Управление социальной адаптацией бывших военнослужащих и членов их семей (1991-2005 г2.): автореф. дис. ... к.соц.н. М. 31 с.

Тощенко Ж.Т. 2011. Социология управления: учебник. М.: Центр социального прогнозирования и маркетинга. 300 с.

Чертушкина Т.А. 2014. Особенности профессиональной подготовки будущих социальных работников в вузе к деятельности с военнослужащими, уволенными в запас: автореф. дис. ... к.пед.н. Ульяновск. 26 с. 
EVENKO Sergey Leonidovich, Dr.Sci. (Psych.), Professor; Head of the Chair of Sociology, Military University of the Ministry of Defense of the Russian Federation (14 Bol'shaya Sadovaya St, Moscow, Russia, 123001; PVRazov@fa.ru) POPOV Igor' Aleksandrovich, Cand.Sci. (Hist.), Associate Professor; Associate Professor of the Chair of Evacuation and Driving Military Tracked and Wheeled Vehicles, Omsk Tank-automotive Engineering Institute of the Ministry of Defense of the Russian Federation (119 14 $4^{\text {th }}$ Gorodok St, Cheremushki settlement, Omsk, Russia, 644098; popov1784@mail.ru)

\title{
GOVERNMENT RISK MANAGEMENT STRATEGIES FOR SOCIAL ADAPTATION OF RUSSIAN SOLDIERS RETIRED
}

Abstract. The article defines and considers various approaches to the state regulation of the process of social adaptation of military personnel dismissed to the reserve, as well as members of their families. The theoretical base of the article is the concept of social planning, expanded within the framework of the risk approach. In their arguments, the authors rely on the results of a sociological study conducted by an expert survey. In conclusion, they describe the effectiveness of existing mechanisms of social support for this group. The authors also cite new promising directions of state regulation of the process of adaptation of retired military personnel, as well as their family members.

Keywords: management mechanisms, management system, social protection, social adaptation, retired military personnel

ВАСИЛЬЕВ Игорь Владимирович - кандидат технических наук, военнослужащий (Россия, Москва; Vasigo@yandex.ru)

\section{ТЕОРЕТИЧЕСКАЯ МОДЕЛЬ СИСТЕМЫ МОБИЛИЗАЦИОННОЙ ПОДГОТОВКИ В РОССИЙСКОЙ ФЕДЕРАЦИИ}

\begin{abstract}
Аннотация. Статья посвящена теоретическому видению современной системы мобилизационной подготовки в Российской Федерации с учетом новых трендов мирового развития. Мобилизационная подготовка рассмотрена в виде социальной системы. Это позволяет раскрыть ее цели и задачи и через составляющие структурные и функциональные компоненты системы, обусловленные современным состоянием развития экономики, технологий и права, смоделировать процессы обеспечения обороноспособности страны и спрогнозировать возможные состояния системы. Проведенный анализ позволит выработать рекомендации для государственных и муниципальных органов управления.
\end{abstract}

Ключевые слова: мобилизационная подготовка, мобилизация, войска, воинские формирования, оборона, право, экономика, военное время, защита, государство, резервы, кадры

нализ современной научной литературы показывает, что теоретико-методо-
илогиеские аспекты исследования проблем мобилизационной подготовки
рабилизационной готовности разработаны крайне слабо: нет попыток раз-
паби теоретических моделей интегрированной системы мобилизационной
подготовки; не исследуются в общем и конкретном виде структурные, функ-
циональные компоненты системы мобилизационной подготовки; не ведутся
работы по конструированию системы знаний, необходимых управленцам в
области мобилизационной подготовки и мобилизации на местном, регио-
нальном и федеральном уровнях, и пр. Представляется, что системное виде-
ние мобилизационной подготовки может высветить целый ряд вопросов, на
которые необходимо ответить в контексте современных вызовов, опасностей и
угроз национальной безопасности Российской Федерации, и расставить при-- 